\title{
Diagnosed, undiagnosed and overall atrial fibrillation research on population over 60 year-old. AFABE study
}

\author{
Josep Lluís Clua-Espuny ${ }^{1}$, Ramon Bosch-Princep², Albert Roso-Llorach ${ }^{3}$, Carlos López-Pablo4* , Emmanuel Giménez-Garcia ${ }^{5}$, Núria \\ González-Rojas ${ }^{6}$, Jorgina Lucas-Noll' ${ }^{1}$ Anna Panisello-Tafalla' ${ }^{1}$, Iñigo Lechuga-Duran7 and Miquel Gallofré-Lopez ${ }^{8}$
}

*Correspondence: clpclp3@gmail.com

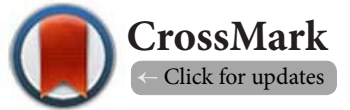

${ }^{1}$ ABS Tortosa-Est Primary Care, Family and Comunity Specialist, Catalan Institute of Health, Regional Management Terres de I'Ebre, CAP Temple, Place carrilet,Tortosa-Spain.

2Department of Research, ICS Terres de I'Ebre, Hospital de Tortosa Verge de la Cinta, Tarragona, Spain.

${ }^{3}$ IDIAP Institute for Research in Primary Care (IDIAP) Barcelona, Spain.

${ }^{4}$ Department of Molecular Biology and Research, Tortosa Verge Cinta Hospital,IDIAP Institute for Research in Primary Care, IISPV and URV,

Spain.

${ }^{5}$ Antares Consulting HEOR, Barcelona, Spain.

${ }^{6}$ Health Economics, Boehringer-Ingelheim España, Sant Cugat del Vallès, Barcelona, Spain.

${ }^{7}$ Department of Cardiology, Tortosa Verge Cinta Hospital, Tortosa Verge Cinta Hospital, Tarragona, Spain.

${ }^{8}$ Director of Catalonia Cerebral Vascular Disease, Health Department of the Government of Catalonia, Barcelona, Spain.

\begin{abstract}
Background: Undiagnosed atrial fibrillation usually is only detected with the first complication. We estimated undiagnosed Atrial Fibrillation prevalence, overall AF and associated factors in a public health-service area in Catalonia, north-eastern Spain.

Methods: Multicentre, cross-sectional study, with people randomly selected among the attended population over 60 years old by primary care teams regardless of follow-up time in health centres or at homes. Information was collected through ECGs, electronic medical history reviews and medical interviews. Descriptive and logistic regression analysis was performed.

Results: 1043 subjects were recruited (47.1\% male), mean age: 73.1 y-o (SD: 7.8 y-o); 43.3\% $\geq 75$-year-old. Overall AF prevalence was $10.9 \%$ (CI95\% 9.1-12.8\%); higher in men than in women, progressively increasing with age (24.4\% in $\geq 85$-year-old). Only women $\geq 85$-year-old had higher prevalence (26.2\%) than men (22.5\%). Undiagnosed AF relative prevalence was $2.2 \%$ (IC $95 \% 1.3-3.1 \%)$. These results show that about 1 in 50 people over 60 years old could suffer undiagnosed AF. The higher risk of AF undiagnosed was found in: men (OR 2.5 IC95\% 1.0-6.2), > 75 years old (OR 2.5 IC95\% 1.0-6.1), heart failure history (OR 5.2 IC95\% 1.3-20.9), who live in rural areas (OR 15.9 IC95\% 1.5-160.1) and to whom no one ECG was performed in the last two years.

Conclusions: The overall AF prevalence increased 10 times from the sixties to over eighties and the proportion man-woman changes from 4:1 to 1:1. The undiagnosed AF prevalence was 2.2\% (IC95\% 1.3-3.1). This percentage should be added to the one of untreated cases with OAC.
\end{abstract}

Keywords: Atrial fibrillation, prevalence, elderly people, diagnosed, undiagnosed, primary care

\section{Introduction}

Atrial fibrillation (AF) is the most common sustained arrhythmia in clinical practice [1] that affects $1-2 \%$ of general population although estimates and projections of diagnosed prevalence of AF have been highly inconsistent across published studies. The life-time risk to develop AF increases with the age and it is higher in man than in women [2]. Due to the ageing population and the increasing prevalence of the known risk factors for $A F$, the number of patients with AF is expected to be the triple in the next four decades as well as its complications, like stroke [3-6]. In addition, the cost of managing AF patients and its complications have been well documented to be high [7]. This will have serious implications for the planning of health and welfare systems, especially not only because of these predictions of AF prevalence continuous increase $[3,8,9]$ but also because the current cost containment economical context. Furthermore, the paroxysmal nature of AF at onset [10] makes difficult to establish the overall AF prevalence and it is still probably underestimated systematically [11] with a percentage ranging from $0.5-1.7 \%$ [12-15]. It has also been demonstrated to be an important cause of the cryptogenic stroke $[16,17]$. An early diagnosis and a treatment are essential to reduce the rate of morbidity and mortality.

The aim of this study was to estimate undiagnosed AF prevalence and the associated risk factors in the population over the sixties who were attended by primary care teams in a public health-service area in Catalonia, north-eastern Spain.

\section{Methods}

AFABE study is a cross-sectional, multicentre study (22 primary 
Clua-Espuny et al. Cardiovascular System 2014,

care centres) in population over 60-year-old attended by primary care teams in Baix Ebre health area in Catalonia, north-eastern Spain, from October 2011 to January 2012. The studied persons were randomly selected among those who were registered and visited at these health centres or at homes, and that means $92.5 \%$ of the overall population who is living in the study's region (Figure 1). In the appointment, one of the two general practitioners enrolled in this study got the consent form, carried out a single resting 12-lead electrocardiogram, revised the electronic medical history and filled in an additional interview. Demographic and relevant clinical co morbidity included in the $\mathrm{CHA}_{2} \mathrm{DS}_{2}$-VASc $[18,19]$ score and previous cardiovascular events and other risk factors for AF were obtained, according the ICD-10 routine classification used in the primary care dataset. Apart from that, stroke risk was measured by, in which a score $\geq 2$ was considered to identify patients at high risk of stroke. All the

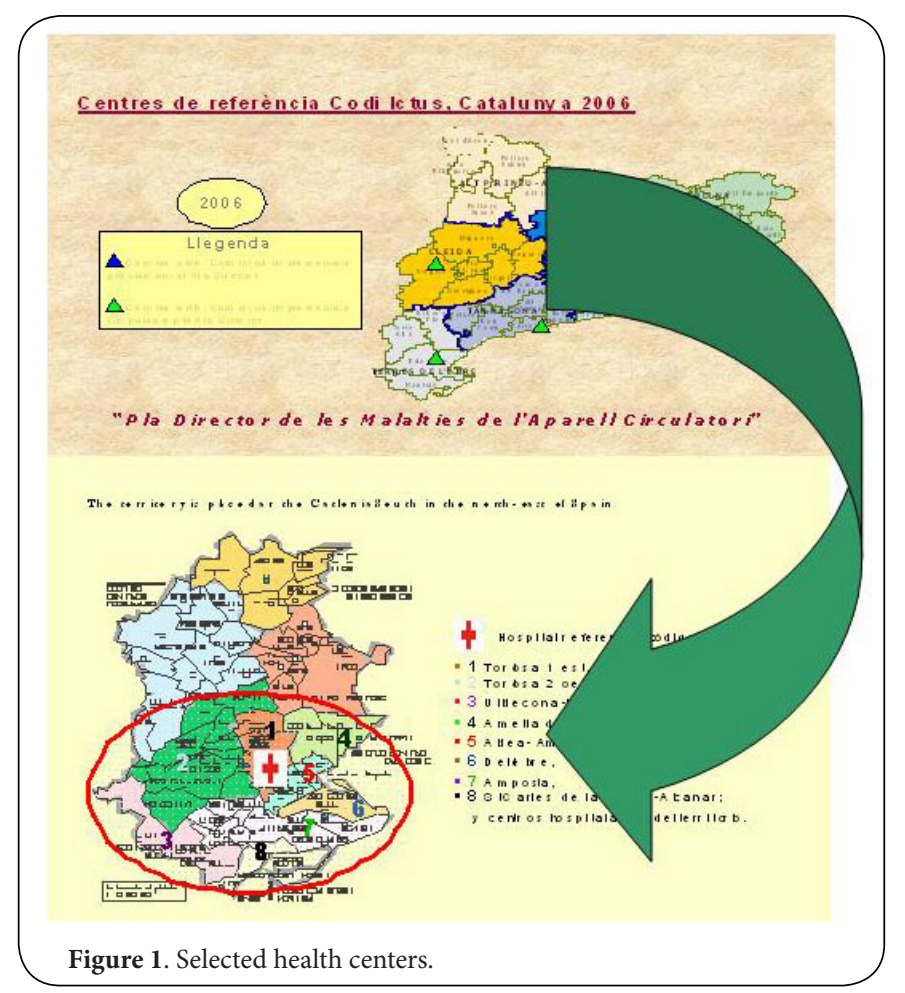

considered clinical conditions were defined in the patient dataset coded using the ICD-10 classification.

The income per capita is significantly lower (93.7\%) from the Catalonia average. Demographically speaking, in the last two decades the gross tax about the total demographic growth is characterized by the natural negative growth, the higher ageing factor and the quickly increase from 2000(12.36/1000 inhab.) to 2006 (26/1000 inhab.) caused by migratory movements which meant a $14.71 \%$ from the actual population. The population over the eighties in the period 1986-2006 has increased its proportion in about a $66 \%$ taking a $3.5 \%$ to
$5.9 \%$ from the total population, without changes between man-woman, but meaning a $60 \%$ of women in the population over 80 years old.

Taking into account the inhabitants of the area ( $\mathrm{N} 82,000)$, the population over the sixties (n 20733), the estimated AF prevalence for Spanish inhabitants (8.5\%) [15] and under the hypothesis of a $34 \%$ of non-diagnosis [1], 600 patients in Baix Ebre area should remained undiagnosed (2.9\% of people over 60-year-old). The sample necessary to analyze for the percentage of undiagnosed patients were 1.029, considering IC95\%, $1 \%$ precision error and $2.9 \%$ hypothesis of undiagnosed AF prevalence. It included a $10 \%$ of people who were attended at their homes or at nursing or care or old people's homes.

The health centres were classified as rural if they were located in towns with $<1,000$ inhabitants, Semi-urban between 1,000 and 10,000 , and Urban $>10,000$. The territory is formed by a low density of population in comparison to the Catalan average, with a tax about a 53.6 inhabitants $/ \mathrm{km} 2$ significantly lower than the Catalan average that is about 212 inhabitants/ $\mathrm{km} 2$. A $46.1 \%$ of inhabitants live in big towns, the $16.4 \%$ in towns with less than 1000 and the rest of them is divided into medium towns.

A patient was considered positive to AF when it could be demonstrated that he or she has or have had at least an AF positive 12-lead ECG [1]. Every patient who presented with $A F$ for the first time was considered a patient with first diagnosed AF and after 8 days of this ECG, a new follow up was done to be classified as persistent or paroxysmal AF [1]. Studied patients could be placed in four groups: 1) Patients always negative for AF; 2) Patients with a current positive ECG and previously diagnosed AF (ICD-10 I48); 3) Patients with a current negative ECG and previously diagnosed AF (ICD-10 148); and 4) Patients with a current positive ECG but previously negative or unknown (previously undiagnosed patients or newly diagnosed patients). We excluded the patients $\leq 60$ years old, without electronic medical history (the individual clinical register was not used at least once in the last three years), and those patients who didn't give their consent.

Different types of AF prevalence (Figure 2) were considered in this article:

1. Overall AF prevalence: percentage of people with at least one documented AF ECG. The patient could be diagnosed at the moment of the study or previously (patients of groups 2, 3 and 4).

2. Previously diagnosed AF prevalence: percentage of patients with a documented AF diagnosis history (patient dataset coded with 148). It was divided in two subgroups:

a. previously diagnosed AF with current positive ECG prevalence: prevalence of patients at group 2 .

b. previously diagnosed AF with current negative ECG prevalence: prevalence of patients at group 3.

3. Undiagnosed AF prevalence: percentage of subjects newly diagnosed of AF during this study (patients of 
group 4) Current AF prevalence: percentage of people with an ECG positive for $A F$ at the moment of performing this study (groups 2 and 4 patients) independently of their previous diagnosis status.

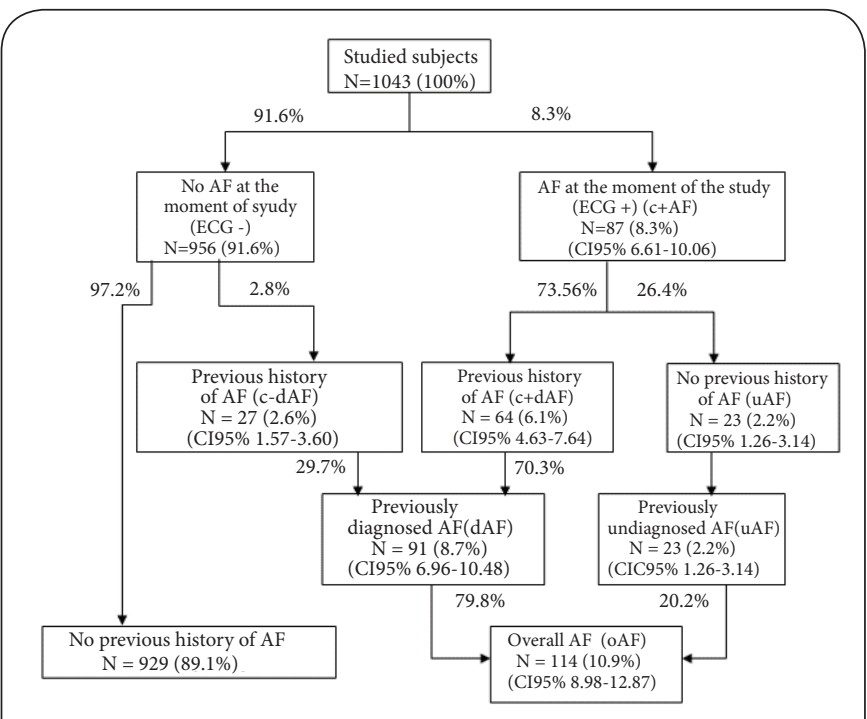

Figure 2. Distribution of the studied subjects and atrial fibrillation prevalences.

N: number of cases; AF: Atrial fibrillation; ECG :

Electrocardiogram negativity for AF; E ECG +:

electrocardiogram positivity for AF; $\mathrm{C}+\mathrm{AF}$ : AF with current positive ECG; uAF: previously undiagnosed AF; dAF:

previously diagnosed AF; $c+d A F$ : previously diagnosed $c+A F$; c-dAF: previously diagnosed with current ECG -; oAF: overall AF.

\section{Statistical analysis}

In the descriptive analysis, data for categorical variables are expressed as number of cases and percentage and, data for continuous variables are expressed as a mean with its standard deviation. Categorical variables were compared using a $x^{2}$ test or Fisher's exact test as required. Continuous variables were compared using Student's test or Mann-Whitney test depending on the normal distribution assumption. Normal distribution was checked by the Shapiro-Wilk test. A logistic regression analysis was performed to find possible risk factors that characterize the population with undiagnosed AF. Factors that were independently associated in the one way analysis, being at least marginally significant $(p \leq 0.1)$ were included using a backward step-wise strategy. A p-value of less than 0.05 was considered to indicate statistical significance. The analysis was carried out with the SPSS statistical software package (version 19).

\section{Results}

1043 people were included in the study. Their average age was 73.1 years old (SD: 7.8 ), and $52.9 \%$ were women. Relevant clinical data related with cardiovascular risk factor are shown in (Table 1). High prevalence of some CVRF was found: hypertension (66.0\%), diabetes mellitus type $2(27.0 \%)$, and myocardial infarction (8.4\%). Three quarters (76.6\%) of the studied population had undergone at least an ECG in the last two years. There were not statistical differences between rural and non-rural populations in demographic and CVRF prevalence. By contrast, there were observed important differences in the prevalence of these CVRF by gender. Men had significantly more prevalence of $\mathrm{DM} 2$, previous stroke, vascular diseases and smoking and in contrast women had been less studied with ECG.

After the ECG performing (Figure 2) 87 (8.3\%) subjects showed an AF positive ECG at the moment of the study. 64 (73.5\%) of these 87 had a previously diagnosed $\mathrm{AF}$ and 23 (26.4\%) had a previously undiagnosed AF. Regarding the 956 (91.6\%) subjects without AF at the moment of study, 27 (2.8\%) subjects had an AF which has been previously registered in their medical history. So, the sum of previously diagnosed AF was at the moment of the study 91 cases.

The distribution of the AF cases after the ECG recording and the prevalence of the different types of $A F$ are illustrated in (Figure 3). The average time from the AF diagnosis was 5.22 years (SD: 3.66 ). The overall AF prevalence was $10.9 \%$ (IC95\% 9.1-12.8) and when it was stratified by gender and age (Figure 3) groups progressively increased from $2.4 \%$ to $24.4 \%$ in patients over 85 years; and men had higher prevalence than women in all age groups except for the group of over 85 -year-old patients in which women reached the highest prevalence detected in this study (26.2\%).

The distribution of the different subtypes of AF by age groups can be appreciated in (Figure 4). Patients from 61 to 69 years had similar low prevalence of the different types of AF that ranged from $0.6 \%$ to $1.3 \%$. Important increases of overall AF prevalence occurred in individuals over 70 years old which increased progressively from 1.4 times for the group of people 65-69 years old, 4.5 times) for 70-74, 5.88 times for $75-79$, 8.1 times for $80-84$ and 10.21 times for $\geq 85$ years old. This huge increase is mainly produced in the prevalence of the previously diagnosed AF (28.5 times) with current positive ECG. We found the main concentration of previously diagnosed AF without current confirmatory in the age groups of 70-74 and $75-79$ years old ( 3.0 times).

The undiagnosed AF prevalence investigated with single ECG recordings for people over the sixties was 2.2\% (IC95\% 1.3-3.1). These results show that about 1 in 50 people over 60 years old could suffer undiagnosed AF. Although it showed an irregular age distribution ranging from $7 \%$ to $37 \%$ of the overall AF prevalence, it increased 6.1 times at the end of the study and represented the $26.4 \%$ (IC95\% 18.3-36.6\%) of the all AF detected in the ECG performed specifically for this study and the $20.2 \%$ (IC95\% 13.8-28.5\%) of the overall AF (Figure 2). After 8 days of follow up, $74 \%$ of undiagnosed AF cases were classified as persistent AF, $14 \%$ as paroxysmal AF and $12 \%$ were lost of follow up; when cases lost of follow up were excluded, 
Clua-Espuny et al. Cardiovascular System 2014,

http://www.hoajonline.com/journals/pdf/2052-4358-2-2.pdf

doi: 10.7243/2052-4358-2-2

Table 1. Study subjects characteristics' and cardiovascular risk factors prevalence by gender and living area.

\begin{tabular}{|c|c|c|c|c|c|c|c|}
\hline & All & Rural & Non-Rural & & Men & Women & \\
\hline Variables & Num. of cases (\%) & Num. of cases (\%) & Num. of cases (\%) & P-value & Num. of cases (\%) & Num. of cases (\%) & P-value \\
\hline \multicolumn{8}{|l|}{ Gender } \\
\hline Men & $491(47.1)$ & $80(46.8)$ & $411(47.1)$ & 0.93 & -- & -- & -- \\
\hline Women & $552(52.9)$ & $91(53.2)$ & $461(52.9)$ & & -- & -- & -- \\
\hline Age $(\geq 75)$ & $452(43.3)$ & $81(47.4)$ & $371(42.5)$ & 0.25 & $222(45.2)$ & $230(41.7)$ & 0.25 \\
\hline $\begin{array}{l}\text { Hyper } \\
\text { tension }\end{array}$ & $688(66.0)$ & $112(65.5)$ & $576(66.1)$ & 0.89 & $331(67.4)$ & $357(64.7)$ & 0.35 \\
\hline $\begin{array}{l}\text { Diabetes } \\
\text { Mellitus }\end{array}$ & $282(27.0)$ & $51(29.8)$ & $231(26.5)$ & 0.37 & $150(30.5)$ & $132(23.9)$ & 0.02 \\
\hline Cardiac failure & $44 \quad(4.2)$ & $6(3.5)$ & $38(4.4)$ & 0.61 & $18(3.7)$ & $26(4.7)$ & 0.40 \\
\hline Stroke & $38 \quad(3.6)$ & $7(4.1)$ & $31(3.6)$ & 0.73 & $24(4.9)$ & $14(2.5)$ & 0.04 \\
\hline TIA & $22(2.1)$ & $5(2.9)$ & $17(1.9)$ & 0.39 & $13(2.6)$ & $9(1.6)$ & 0.25 \\
\hline $\begin{array}{l}\text { Throm } \\
\text { boembolism }\end{array}$ & $8(0.8)$ & $2(1.2)$ & $6(0.7)$ & 0.62 & $5(1.0)$ & $3(0.5)$ & 0.49 \\
\hline Vascular disease & $111(10.7)$ & $11(6.4)$ & $100(11.5)$ & 0.05 & $75(15.3)$ & $36(6.5)$ & $<0.001$ \\
\hline \multicolumn{8}{|l|}{ Smoking } \\
\hline Ex-smokers & $188(18.4)$ & $33(19.9)$ & $155(18.1)$ & 0.77 & $177(36.8)$ & $11(2.0)$ & $<0.001$ \\
\hline Current smokers & $67(6.5)$ & $12(7.2)$ & $55(6.4)$ & -- & $58(12.1)$ & $9(1.7)$ & -- \\
\hline No smokers & $768(75.1)$ & $121(72.9)$ & $674(75.5)$ & -- & $246(51.1)$ & $522(96.3)$ & -- \\
\hline $\begin{array}{l}\text { ECG in the last } \\
2 \text { years }\end{array}$ & $800(76.7)$ & $131(76.6)$ & $669(76.7)$ & 0.97 & $395(80.4)$ & $405(73.4)$ & 0.007 \\
\hline $\begin{array}{l}\text { Previous } \\
\text { symptoms }\end{array}$ & $283(27.2)$ & $36(21.1)$ & $247(28.4)$ & 0.05 & $110(22.4)$ & $173(31.4)$ & $<0.001$ \\
\hline Age, mean (y) & 73.1 (SD:7.8) & 74.1 (SD:8.3) & 72.9 (SD:7.7) & 0.06 & 73.3 (SD:7.8) & 73.0 (SD:7.8) & 0.49 \\
\hline
\end{tabular}

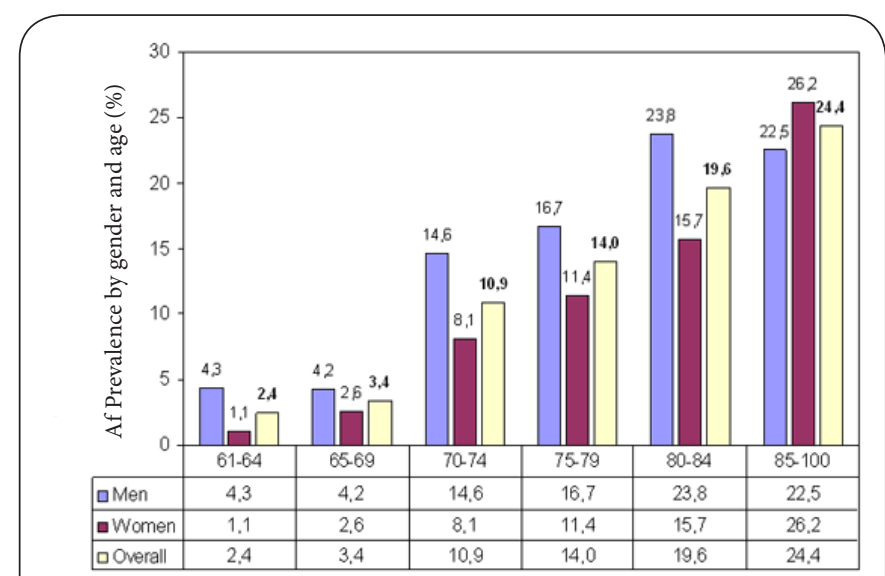

Figure 3. Distribution of overall AF prevalence by gender and by age groups.

$85 \%$ corresponded to persistent $\mathrm{AF}$ and a $15 \%$ to paroxysmal $\mathrm{AF}$. (Table 2) shows the results of comparing demographic characteristics and the prevalence of the cardiovascular risk factors for the different subtypes of AF. Subjects with AF had significantly higher prevalence of most of the AF risk factors than the subjects without AF. The undiagnosed AF patients had not significantly differences in age ( $p 0.61)$, gender ( $p 0.54)$,

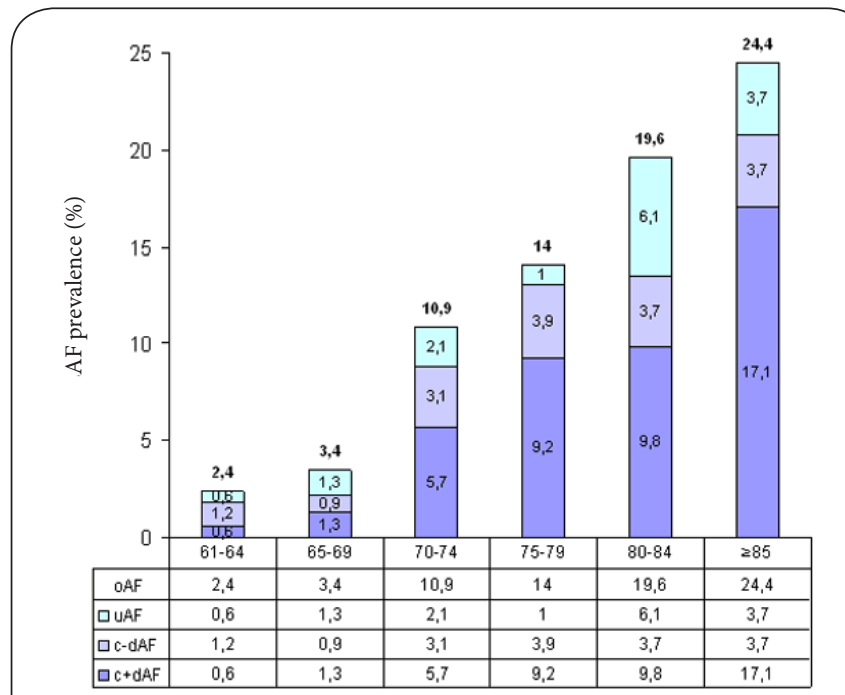

Figure 4. Prevalence distribution of the different types of $\mathrm{AF}$ by age groups.

c+AF: AF with current positive ECG; uAF: previously undiagnosed AF; dAF: previously diagnosed AF; c+dAF: previously diagnosed c+AF; c-dAF: previously diagnosed with current ECG -; oAF: overall AF.

hypertension prevalence ( $p$ 0.29) or DM2 ( $p 0.25)$, antecedents 
Table 2. Subjects characteristics and cardiovascular risk factors prevalence in sane subjects, AF affected patients and by the different type of AF.

\begin{tabular}{|c|c|c|c|c|c|c|c|c|}
\hline Subjects & $\begin{array}{l}\text { Without AF } \\
(929)\end{array}$ & $\begin{array}{l}\text { With AF } \\
(114)\end{array}$ & $\mathbf{P}$ & $\begin{array}{l}\text { Current - ECG } \\
\text { Previously } \\
\text { Diagnosed (27) }\end{array}$ & $\begin{array}{l}\text { Current ECG } \\
+ \text { Previously } \\
\text { Diagnosed (64) }\end{array}$ & $\begin{array}{l}\text { Previously } \\
\text { Undiagnosed } \\
\text { AF }(23)\end{array}$ & $\begin{array}{l}\mathrm{p}(\mathrm{uAF} \\
\mathrm{vs}+\mathrm{dAF})\end{array}$ & $\begin{array}{l}\mathrm{p}(\mathrm{uAF} \\
\text { vs c-dAF })\end{array}$ \\
\hline Women (\%) & $503(54.1)$ & $49(43)$ & 0.02 & $14(51.9)$ & $27(42.2)$ & $8(34.8)$ & 0.54 & 0.23 \\
\hline Mean age (years) & $72.44 \pm 7.59$ & $78.7 \pm 7.30$ & $<0.001$ & $76.67 \pm 7.48$ & $79.55 \pm 6.90$ & $78.65 \pm 8.03$ & 0.61 & 0.37 \\
\hline Age ( $\geq 75$ y.) & $371(39.9)$ & $81(71.1)$ & $<0.001$ & $17(63.0)$ & $49(76.6)$ & $15(65.2)$ & 0.29 & 0.87 \\
\hline Hypertension (\%) & $600(64.6)$ & $88(77.2)$ & 0.007 & $24(88.9)$ & $49(76.6)$ & $15(65.2)$ & 0.29 & 0.04 \\
\hline Diabetes mellitus (\%) & $256(27.6)$ & $26(22.8)$ & 0.28 & $7(25.9)$ & $12(18.8)$ & $7(30.4)$ & 0.25 & 0.72 \\
\hline Vascular disease (\%) & $90(9.7)$ & $21(18.4)$ & 0.004 & $6(22.2)$ & $14(219)$ & $1(4.3)$ & 0.10 & 0.11 \\
\hline $\begin{array}{l}\text { Previous } \\
\text { stroke / TIA (\%) }\end{array}$ & $42(4.5)$ & $14(12.3)$ & 0.001 & $5(18.5)$ & $8(12.5)$ & $1(4.3)$ & 0.43 & 0.2 \\
\hline Heart failure (\%) & $19(2.0)$ & $25(21.9)$ & $<0.001$ & $4(14.8)$ & $18(28.1)$ & $3(13.0)$ & 0.15 & 1.00 \\
\hline $\begin{array}{l}\text { Throm } \\
\text { boembolism (\%) }\end{array}$ & $8(0.9)$ & $0(0)$ & 1.00 & $0(0)$ & $0(0)$ & $0(0)$ & NA & NA \\
\hline $\begin{array}{l}\text { CHA2 } \\
\text { D2VASc score } \geq 2(\%)\end{array}$ & $797(85.9)$ & $109(95.6)$ & 0.004 & $25(92.6)$ & $63(98.4)$ & $21(91.3)$ & 0.17 & 1.00 \\
\hline $\begin{array}{l}\text { ECG in the last } 2 \\
\text { years }(\%)\end{array}$ & $694(74.7)$ & $106(93.0)$ & $<0.001$ & $25(92.6)$ & $62(96.9)$ & $19(82.6)$ & 0.04 & 0.40 \\
\hline $\begin{array}{l}\text { Previous symptoms } \\
(\%)\end{array}$ & $220(23.7)$ & $63(55.3)$ & $<0.001$ & $18(66.7)$ & $35(54.7)$ & $10(43.5)$ & 0.36 & 0.1 \\
\hline \multicolumn{9}{|l|}{ Type of population (\%) } \\
\hline Rural & $152(16.4)$ & $19(16.7)$ & & $5(18.5)$ & $10(15.6)$ & $4(17.4)$ & -- & -- \\
\hline Semi urban & $352(37.9)$ & $39(34.2)$ & 0.73 & $9(33.3)$ & $20(31.2)$ & $10(43.5)$ & 0.49 & 0.75 \\
\hline Urban & $425(45.7)$ & $56(49.1)$ & & $13(48.1)$ & $34(53.1)$ & $9(39.1)$ & & \\
\hline $\begin{array}{l}\text { No oral anticoa } \\
\text { gulation }(\%)\end{array}$ & $928(99.9)$ & $41(36.9)$ & $<0.001$ & $15(60)$ & $8(12.7)$ & $18(78.3)$ & $<0.001$ & 0.17 \\
\hline
\end{tabular}

of vascular diseases as ischemic cardiopathy, stroke or TIA and heart failure ( $p 0.10), \mathrm{CHA}_{2} \mathrm{DS}_{2}$-VASc score ( $p$ 0.17). There were significant differences in a lower prevalence of treatment with OAC $(12.7 \%$ versus $78.3 \%, \mathrm{p}<0.001)$ and in the practice of an ECG in the last two years ( $82.6 \%$ versus $96.9 \%, p=0.04$ ).

The logistic regression analysis (Table 3 ) showed that the undiagnosed AF was associated with the profile of a 75-yearold man with previous medical history of heart failure, who lives in a rural area and has not had any ECG performed in the last two years. The interaction between "to be from rural areas ( $<1000$ inhabitants)" and "to have an ECG performed in the last two years" was statistically significant $(p=0.013)$. The variable "rural" carried a high risk of undiagnosed AF but when an ECG was performed, it had a high protective effect (OR 0.02 IC95\% 0.00-0.44).

\section{Discussion}

It is generally acknowledged that AF incidence and prevalence are increasing due to growing numbers of older people but a wide range of uncertainty exists around the magnitude of future trends by differences in study design, covered time period, birth cohort, and temporal effects. There are as well as improvements in AF diagnosis due to increased use of
Table 3. Multivariate logistic regression analysis with factors that characterized the undiagnosed AF population.

\begin{tabular}{lll}
\hline Independent variables & OR ( 95\% CI $)$ & P-value \\
\hline Genre: Men & $2.503(1.001-6.261)$ & 0.050 \\
Age: $\geq 75$ years & $2.526(1.041-6.132)$ & 0.041 \\
$\begin{array}{l}\text { Previous symptoms in last 2 years: } \\
\text { Yes }\end{array}$ & $2.384(0.962-5.907)$ & 0.060 \\
Heart failure: Yes & $5.253(1.318-20.927)$ & 0.019 \\
$\begin{array}{l}\text { ECG in the last 2 years: No } \\
\text { Rural environment: Yes }\end{array}$ & $3.906(0.506-30.162)$ & 0.191 \\
$\begin{array}{l}\text { Rural environment }{ }^{*} \text { ECG in the last } \\
\text { years: Yes }\end{array}$ & $0.020(0.001-0.441)$ & 0.013 \\
\hline
\end{tabular}

OR: Odds ratio; 95\% CI: 95\% Confidence interval

diagnostic tools and health care awareness [20]. This report is one of many articles dealing with the AF in developed countries, but gives special emphasis incorporating the undiagnosed population, a segment of the patient population most often overlooked. It tries to quantify undiagnosed AF prevalence and has evaluated the factors associated with the undiagnosed AF. We found an overall AF prevalence of $10.9 \%$ and previously 
Clua-Espuny et al. Cardiovascular System 2014,

http://www.hoajonline.com/journals/pdf/2052-4358-2-2.pdf

doi: 10.7243/2052-4358-2-2

undiagnosed AF of $2.2 \%$. These data means that a $20.2 \%$ of the overall AF cases were undiagnosed. In addition, that overall AF prevalence increases with age especially in individuals over 70 years old. From the sixties to over eighties the prevalence increases by 10 times and the relationship between man and woman changes from 4:1 to 1:1. Eventually this percentage of undiagnosed $A F$ should be added to percentage of known FA no treated with ACO which would mean about $40-50 \%$ [21] of overall AF. In the study's territory, the percentage of people over 80 years old increased $68 \%$ in the period 1986 2006 which means the proportion of people over this age increases from the 3.5\% to 6\% [22] from which 60\% are female. Clearly, it should have serious implications for the planning of health and welfare systems not only because of global burden of continuous increase $[3,8,9]$ of AF prevalence, but because the undiagnosed group is not treated with OCA and should be included in many studies which found an underuse of oral anticoagulants in atrial fibrillation [14,23-25] and by the increased benefit of the OCA elderly of the patients [26]. The lower share of the population with AF that is diagnosed the lower will be the share with anticoagulation treatment. Each patient with AF and thromboembolic risk factors who is not treated with anticoagulation will, in monetary terms, be in on an added financial burden on society [27-29], which is double that of the treated patient, because of their higher risk for brain vascular complications. Because a majority of patients with AF with increased risk for stroke had not received anticoagulation therapy, there is a large potential for improvement if the primary care professionals take a more proactive attitude of opportunistic case finding, regardless of the reason of the patient's visit.

When additionally it was stratified by sex, overall AF had a higher prevalence in men in all age groups except in group over the eighties, where women achieved the highest prevalence. This fact has been also observed in few articles $[13,15,30,31]$. In a recent study, it has been found a slight decrease in the AF prevalence in people older than 85 years old for both, men and women [32] but in fact that article mentioned that woman never went beyond men AF prevalence.

It exists a wide range of uncertainty $[20,32-34]$ around the AF studies design. It is well known that AF prevalence is considerably higher in hospitalized patients especially in internal medicine and geriatric wards ( $31 \%$ for patients $\geq 70$-year-old) [35] than in primary care [36-38]. We included a proportional sample of the subjects who were attended at their homes or at nursing care or old people's homes. Given the patients who did not visit the centre in the past 3 years, they have been excluded, presumably these relatively healthier individuals may be less likely to be diagnosed with $\mathrm{AF}$ and therefore the prevalence estimates that the paper may be exaggerated. However, the analysis of the primary care systems' use excludes the $7.5 \%$ of the rest of the population with risk to suffer from AF.

The particular paroxysmal nature of most AF cases at its starting point [10] makes difficult to establish the true AF incidence. In addition, as we have observed in this study, an important part of these patients with cardiovascular co morbidities have not got an ECG in the last two years. It is for all these arguments that using just an ECG study is probably not sensible enough to diagnose a new AF. Because of that, other studies tried to combine at least a single ECG with medical records review $[15,36,38,39]$ and some use other mixed strategies $[40]$ in order to improve the probability of AF detection: patient's medical history review; ECG recording [41] (24-48 hour Holter monitoring) but its high cost presents a major obstacle in large studies and may underestimate the true prevalence of $A F$, mainly the paroxysmal AF particularly if the burden is low [43]; cardiac invasive devices that detected a $42 \%$ of undiagnosed AF [43] and have substantially improved the detection of silent paroxysmal AF in patients with a recent ischemic stroke/TIA [44]. Nevertheless, until these new external devices can be broadly used, and probably in our socioeconomic context, the ECG study combined with medical history review will still be the best non-invasive feasible strategy to identify individuals with AF.

In this study we have used the term "Overall AF prevalence", that have been used in epidemiologic studies by several authors $[2,32,45]$ to refer the sum of previously undiagnosed and previously diagnosed AF prevalence. One of the most striking finding of this work has been the high overall AF prevalence that we observed. The fact that our study was performed in a primary care context and included a $10 \%$ of the studied people who were attended at their homes or at nursing care or old people's homes, probably influenced in this high prevalence. Some studies $[12,32]$ have speculated that these people could produce an increase of the AF prevalence. Previous studies $[14,15,36]$ obtained a prevalence between $6.1-10.2 \%$ although included patients $\geq 18$-year-old, or did not include patients visited at home or at care institutions, or excluded undiagnosed AF.

We also defined "Undiagnosed AFprevalence" as the percentage of people with an AF positive ECG performed at the moment of the study who did not have any previous medical record of an AF diagnosis independent of they had or not been previously studied. This term has also been previously used by few authors [12-15]. Other authors have used it as equivalent to prevalence of newly diagnosed AF [38] detected in some screening studies, or as the term undetected $\mathrm{AF}[\mathbf{4 2 , 4 6 ]}$, and as unrecognized AF [47]. In our study represented a $2.2 \%$ of previously undiagnosed or the $20.2 \%$ of overall AF. In others[33,48] it was between $25-35 \%$; or newly diagnosed AF (SAFE, England) [38] of 1.63\%; or undiagnosed AF $\geq 85$-year-old (England) [49] of 3,8\%; (Norway) [12] of 1\%; (Spain) [13-15] of $0,5-1,7 \%$.

The logistic regression analysis performed in this study also demonstrated that age over 75 years old, men gender, previous chronic heart failure history, an absence of a previous ECG in the last two years and living in rural environment were the 
major risk factor to have an undiagnosed AF. This supports the idea this person could also be the result of an inadequate evaluation especially those with these clinical and demographic characteristics, and this reinforces the idea that AF screening must not be just a current opportunistic activity, but it should be an active practice to identify additional AF cases. It has been clearly demonstrated [36] that active screening for AF detects additional cases over current practice and that the most efficient method of screening is opportunistic pulse taking with follow-up electrocardiography specially in patients with multiple cardiovascular conditions [50]. On other hand, the evolution of the primary care attention in our country is lead to evaluation and distribution of the sanitary resources taking into account the concentration of the population. This fact together with the ageing of the population could provoke differences on accessibility, especially in those smaller central populations where precisely the older population live. This reason would be the explanation of the results of undiagnosed AF.

Since this is a study of subjects registered in the public primary care system, it is possible that a higher frequentation of $\mathrm{AF}$ patients or patients with AF risk in a context of high ageing population could produce an artificial increase of prevalence described. However, since an ECG performing is not a highly sensitive system to detect AF prevalence we should expect that a portion of them with AF could have not been detected.

\section{Conclusions}

The overall AF prevalence is $10.9 \%$ for $>60$-year-old people and it is strongly associated with ageing and male gender; from the sixties to the eighties increased by 10 times and changed the proportion man/woman from 4:1 to 1:1. The undiagnosed AF was 2.2\% (Cl95\% 1.3-3.1). In this percentage untreated cases with OAC should be added.

These were associated with higher risk of $\mathrm{AF}$ undiagnosed: men (OR 2.5 Cl95\% 1.0-6.2), > 75 years old (OR $2.5 \mathrm{Cl} 195 \%$ 1.06.1), heart failure history (OR $5.2 \mathrm{CI} 95 \%$ 1.3-20.9), who live in rural areas (OR $15.9 \mathrm{Cl}$ (95\% 1.5-160.1) and to whom no one ECG was performed in the last two years.

\section{List of abbreviations}

AF: Atrial fibrillation

AFABE: Atrial Fibrillation Audit in Baix Ebre

$\mathrm{CHA}_{2} \mathrm{DS}_{2}$-VASc: Congestive heart failure (or Left ventricular systolic dysfunction), Hypertension: blood pressure consistently above $140 / 90 \mathrm{mmHg}$ (or treated hypertension on medication), Age $\geq 75$ years, Diabetes Mellitus, Prior Stroke or TIA or thromboembolism, Vascular disease (e.g., peripheral artery disease, myocardial infarction, aortic plaque), Age 65-74 years old, Sex category (i.e., female gender) CVRF: Cardiovascular risk factor

DM2: diabetes mellitus type 2

ECG: Electrocardiogram

GP: General practitioner
HAS-BLED: Hypertension, Abnormal renal/liver function, Stroke, Bleeding history or predisposition, Labile INR, Elderly, Drugs/alcohol concomitantly

HF: Heart failure

OAC: Oral anticoagulation

PC: Primary care

SD: Standard Deviation

TIA:Transient Ischemic Attack.

\section{Competing interests}

The authors declare that they have no competing interests.

\section{Authors' contributions}

\begin{tabular}{|l|c|c|c|c|c|c|c|c|c|c|}
\hline $\begin{array}{l}\text { Authors' } \\
\text { contributions }\end{array}$ & JLCE & RBP & ARL & CLP & EGG & NGR & JLN & APT & ILD & MGL \\
\hline $\begin{array}{l}\text { Research } \\
\text { concept and } \\
\text { design }\end{array}$ & $\checkmark$ & $\checkmark$ & $\checkmark$ & $\checkmark$ & $\checkmark$ & $\checkmark$ & $\checkmark$ & $\checkmark$ & $\checkmark$ & $\checkmark$ \\
\hline $\begin{array}{l}\text { Collection } \\
\text { and/or } \\
\text { assembly of data }\end{array}$ & -- & -- & $\checkmark$ & -- & -- & -- & $\checkmark$ & $\checkmark$ & $\checkmark$ & - \\
\hline $\begin{array}{l}\text { Data analysis } \\
\text { and } \\
\text { interpretation }\end{array}$ & $\checkmark$ & $\checkmark$ & $\checkmark$ & $\checkmark$ & $\checkmark$ & $\checkmark$ & $\checkmark$ & $\checkmark$ & $\checkmark$ & $\checkmark$ \\
\hline $\begin{array}{l}\text { Writing the } \\
\text { article }\end{array}$ & $\checkmark$ & $\checkmark$ & $\checkmark$ & $\checkmark$ & $\checkmark$ & $\checkmark$ & -- & -- & -- & - \\
\hline $\begin{array}{l}\text { Critical revision } \\
\text { of the article }\end{array}$ & $\checkmark$ & $\checkmark$ & $\checkmark$ & $\checkmark$ & $\checkmark$ & $\checkmark$ & $\checkmark$ & $\checkmark$ & $\checkmark$ & $\checkmark$ \\
\hline $\begin{array}{l}\text { Final approval of } \\
\text { article }\end{array}$ & $\checkmark$ & $\checkmark$ & $\checkmark$ & $\checkmark$ & - & -- & $\checkmark$ & $\checkmark$ & $\checkmark$ & $\checkmark$ \\
\hline $\begin{array}{l}\text { Statistical } \\
\text { analysis }\end{array}$ & $\checkmark$ & $\checkmark$ & $\checkmark$ & $\checkmark$ & - & -- & - & - & -- & - \\
\hline
\end{tabular}

\section{Acknowledgement}

We thank Cerebral Vascular Disease' Management Plan in Catalonia, Health Department Generalitat de Catalunya contributed towards the work in design of this study and Boehringer-Ingelheim (Spain Sant Cugat del Valles, Barcelona) provided the funding source for data acquisition.

\section{Publication history}

EIC: William Clifford Roberts, Baylor University Medical Center, USA Received: 10-Dec-2013 Revised: 15-Jan-2014

Re-Revised: 04-Feb-2014 Accepted: 11-Feb-2014

Published: 19-Feb-2014

\section{References}

1. Camm AJ, Lip GY, De Caterina R, Savelieva I, Atar D, Hohnloser SH, Hindricks G and Kirchhof P. 2012 focused update of the ESC Guidelines for the management of atrial fibrillation: an update of the 2010 ESC Guidelines for the management of atrial fibrillation. Developed with the special contribution of the European Heart Rhythm Association. Eur Heart J. 2012; 33:2719-47. | Article | PubMed

2. Heeringa J, van der Kuip DA, Hofman A, Kors JA, van Herpen G, Stricker BH, Stijnen T, Lip GY and Witteman JC. Prevalence, incidence and lifetime risk of atrial fibrillation: the Rotterdam study. Eur Heart J. 2006; 27:949-53. | Article | PubMed

3. Stefansdottir H, Aspelund T, Gudnason V and Arnar DO. Trends in the incidence and prevalence of atrial fibrillation in Iceland and future projections. Europace. 2011; 13:1110-7. I Article I PubMed

4. Harmsen $P$, Wilhelmsen $L$ and Jacobsson $A$. Stroke incidence and mortality rates 1987 to 2006 related to secular trends of cardiovascular risk factors in Gothenburg, Sweden. Stroke. 2009; 40:2691-7. | Article | PubMed 
Clua-Espuny et al. Cardiovascular System 2014,

5. Hughes $M$ and Lip GY. Stroke and thromboembolism in atrial fibrillation: a systematic review of stroke risk factors, risk stratification schema and cost effectiveness data. Thromb Haemost. 2008; 99:295-304. | Article | PubMed

6. Potpara TS, Stankovic GR, Beleslin BD, Polovina MM, Marinkovic JM, Ostojic MC and Lip GY. A 12-year follow-up study of patients with newly diagnosed lone atrial fibrillation: implications of arrhythmia progression on prognosis: the Belgrade Atrial Fibrillation study. Chest. 2012; 141:339-47. I Article | PubMed

7. Wodchis WP, Bhatia RS, Leblanc $K$, Meshkat $N$ and Morra D. A review of the cost of atrial fibrillation. Value Health. 2012; 15:240-8. | Article | PubMed

8. Miyasaka Y, Barnes ME, Gersh BJ, Cha SS, Bailey KR, Abhayaratna WP, Seward JB and Tsang TS. Secular trends in incidence of atrial fibrillation in Olmsted County, Minnesota, 1980 to 2000, and implications on the projections for future prevalence. Circulation. 2006; 114:119-25. | Article | PubMed

9. Naccarelli GV, Varker H, Lin J and Schulman KL. Increasing prevalence of atrial fibrillation and flutter in the United States. Am J Cardiol. 2009; 104:1534-9. | Article | PubMed

10. Kirchhof $P$, Auricchio A, Bax J, Crijns H, Camm J, Diener HC, Goette $A$, Hindricks G, Hohnloser S, Kappenberger L, Kuck KH, Lip GY, Olsson B, Meinertz T, Priori S, Ravens U, Steinbeck G, Svernhage E, Tijssen J, Vincent $A$ and Breithardt $G$. Outcome parameters for trials in atrial fibrillation: executive summary. Eur Heart J. 2007; 28:2803-17. | Article I PubMed

11. Prystowsky EN, Camm J, Lip GY, Allessie M, Bergmann JF, Breithardt G, Brugada J, Crijns H, Ellinor PT, Mark D, Naccarelli G, Packer D and Tamargo J. The impact of new and emerging clinical data on treatment strategies for atrial fibrillation. J Cardiovasc Electrophysiol. 2010; 21:94658. | Article | PubMed

12. Tveit $A$, Abdelnoor $M$, Enger $S$ and Smith P. Atrial fibrillation and antithrombotic therapy in a 75-year-old population. Cardiology. 2008; 109:258-62. | Article | PubMed

13. Labrador Garcia MS, Merino Segovia R, Jimenez Dominguez C, Garcia Salvador Y, Segura Fragoso A and Hernandez Lanchas C. [Prevalence of auricular fibrillation in people over 65 years of age in a health area]. Aten Primaria. 2001; 28:648-51. | Article | PubMed

14. Morillas P, Pallares V, Llisterri JL, Sanchis C, Sanchez T, Facila L, PerezAlonso M, Castillo J, Redon J and Bertomeu V. Prevalence of atrial fibrillation and use of antithrombotics in hypertensive patients aged $>$ or $=65$ years. The FAPRES trial. Rev Esp Cardiol. 2010; 63:943-50. | PubMed

15. Cea-Calvo L, Redon J, Lozano JV, Fernandez-Perez C, Marti-Canales JC, Llisterri JL, Gonzalez-Esteban J and Aznar J. [Prevalence of atrial fibrillation in the Spanish population aged 60 years or more. The PREVICTUS study]. Rev Esp Cardiol. 2007; 60:616-24. | Article | PubMed

16. Sinha AM, Diener HC, Morillo CA, Sanna T, Bernstein RA, Di Lazzaro V, Passman R, Beckers F and Brachmann J. Cryptogenic Stroke and underlying Atrial Fibrillation (CRYSTAL AF): design and rationale. Am Heart J. 2010; 160:36-41 e1. | Article | PubMed

17. Friberg $L$, Hammar $N$ and Rosenqvist $M$. Stroke in paroxysmal atrial fibrillation: report from the Stockholm Cohort of Atrial Fibrillation. Eur Heart J. 2010; 31:967-75. | Article | PubMed

18. Gage BF, Waterman AD, Shannon W, Boechler M, Rich MW and Radford MJ. Validation of clinical classification schemes for predicting stroke: results from the National Registry of Atrial Fibrillation. JAMA. 2001; 285:2864-70. | Article | PubMed

19. Pamukcu B, Lip GY and Lane DA. Simplifying stroke risk stratification in atrial fibrillation patients: implications of the CHA2DS2-VASc risk stratification scores. Age Ageing. 2010; 39:533-5. | Article | PubMed

20. Colilla S, Crow A, Petkun W, Singer DE, Simon T and Liu X. Estimates of current and future incidence and prevalence of atrial fibrillation in the U.S. adult population. Am J Cardiol. 2013; 112:1142-7. | Article | PubMed

21. Josep L, Clua-Espuny, Iñigo Lechuga-Duran, Ramón Bosch-Princep, Albert Roso-Llorach, Anna Panisello-Tafalla, Jorgina Lucas-Noll, Carles López-
Pablo, Lluïsa Queralt-Tomas, Emmanuel Giménez-Garcia, Núria GonzálezRojas and Miquel Gallofré López. Prevalencia de la fibrilación auricular desconocida y la no tratada con anticoagulantes. Estudio AFABE. Rev Esp Cardiol. 2013; 66:545-552. | Article

22. IdesCat. Població segons sexe i edat quinquennal Baix Ebre. 2011. | Website

23. Ogilvie IM, Newton N, Welner SA, Cowell W and Lip GY. Underuse of oral anticoagulants in atrial fibrillation: a systematic review. Am J Med. 2010; 123:638-645 e4. | Article | PubMed

24. Lip GY and Lane DA. Tratamiento anticoagulante y antiagregante plaquetario combinado en pacientes con fibrilación auricular. Rev Esp Cardiol. 2009; 62:972-975. | Pdf

25. Lip GY, Brechin CM and Lane DA. The global burden of atrial fibrillation and stroke: a systematic review of the epidemiology of atrial fibrillation in regions outside North America and Europe. Chest. 2012; 142:1489-98. | Article | PubMed

26. van Walraven C, Jennings A, Oake N, Fergusson D and Forster AJ. Effect of study setting on anticoagulation control: a systematic review and metaregression. Chest. 2006; 129:1155-66. | Article | PubMed

27. Holstenson E, Ringborg A, Lindgren P, Coste F, Diamand F, Nieuwlaat R and Crijns $\mathrm{H}$. Predictors of costs related to cardiovascular disease among patients with atrial fibrillation in five European countries. Europace. 2011; 13:23-30. | Article | PubMed

28. Lopez Gude MJ, Rodriguez Bezos D and Rodriguez Barrios JM. [Costbenefit analysis of concomitant atrial fibrillation management in Spain]. Gac Sanit. 2010; 24:59-65. | Article | PubMed

29. Staffan Björck; Bo Palaszewski; Leif Friberg; Lennart Bergfeldt. Atrial Fibrillation, Stroke Risk, and Warfarin Therapy Revisited. A PopulationBased Study. Stroke. 2013; 44:3103-3108. | Article

30. Davis RC, Hobbs FD, Kenkre JE, Roalfe AK, lles R, Lip GY and Davies MK. Prevalence of atrial fibrillation in the general population and in highrisk groups: the ECHOES study. Europace. 2012; 14:1553-9. | Article | PubMed

31. Majeed A, Moser K and Carroll K. Trends in the prevalence and management of atrial fibrillation in general practice in England and Wales, 1994-1998: analysis of data from the general practice research database. Heart. 2001; 86:284-8. | Article | PubMed Abstract | PubMed Full Text

32. Andersson $\mathrm{P}$, Londahl M, Abdon $\mathrm{NJ}$ and Terent $\mathrm{A}$. The prevalence of atrial fibrillation in a geographically well-defined population in northern Sweden: implications for anticoagulation prophylaxis. J Intern Med. 2012; 272:170-6. | Article | PubMed

33. Fitzmaurice DA. Routine screening for detection of atrial fibrillation? Future Cardiol. 2009; 5:213-4. | Article | PubMed

34. Schmutz M, Beer-Borst S, Meiltz A, Urban P, Gaspoz JM, Costanza MC, Morabia $A$ and Zimmermann $M$. Low prevalence of atrial fibrillation in asymptomatic adults in Geneva, Switzerland. Europace. 2010; 12:47581. | Article | PubMed

35. Lopez Soto A, Formiga F, Bosch X and Garcia Alegria J. [Prevalence of atrial fibrillation and related factors in hospitalized old patients: ESFINGE study]. Med Clin (Barc). 2012; 138:231-7. | Article | PubMed

36. Barrios V, Calderon A, Escobar C and de la Figuera M. Patients with atrial fibrillation in a primary care setting: Val-FAAP study. Rev Esp Cardiol (Engl Ed). 2012; 65:47-53. | Article | PubMed

37. Mashal A, Katz A and Shvartzman P. Atrial fibrillation: a primary care cross-sectional study. Isr Med Assoc J. 2011; 13:666-71. | Article | PubMed

38. Fitzmaurice DA, Hobbs FD, Jowett $S$, Mant J, Murray ET, Holder R, Raftery JP, Bryan S, Davies M, Lip GY and Allan TF. Screening versus routine practice in detection of atrial fibrillation in patients aged 65 or over: cluster randomised controlled trial. BMJ. 2007; 335:383. | Article | PubMed Abstract | PubMed Full Text

39. Wolf PA, Abbott RD and Kannel WB. Atrial fibrillation as an independent risk factor for stroke: the Framingham Study. Stroke. 1991; 22:983-988. | Article

40. Furberg CD, Psaty BM, Manolio TA, Gardin JM, Smith VE and 
Rautaharju PM. Prevalence of atrial fibrillation in elderly subjects (the Cardiovascular Health Study). Am J Cardiol. 1994; 74:236-41. | Article | PubMed

41. Prineas RJ, Soliman EZ, Howard G, Howard VJ, Cushman M, Zhang $\mathrm{ZM}$ and Moy CS. The sensitivity of the method used to detect atrial fibrillation in population studies affects group-specific prevalence estimates: ethnic and regional distribution of atrial fibrillation in the REGARDS study. J Epidemiol. 2009; 19:177-81. | Article | PubMed Abstract | PubMed Full Text

42. Caldwell JC, Contractor H, Petkar S, Ali R, Clarke B, Garratt CJ, Neyses $L$ and Mamas MA. Atrial fibrillation is under-recognized in chronic heart failure: insights from a heart failure cohort treated with cardiac resynchronization therapy. Europace. 2009; 11:1295-300. | Article | PubMed

43. Puglisi A, Gasparini M, Lunati $M$, Sassara M, Padeletti L, Landolina $M$, Botto GL, Vincenti A, Bianchi S, Denaro A, Grammatico A and Boriani G. Persistent atrial fibrillation worsens heart rate variability, activity and heart rate, as shown by a continuous monitoring by implantable biventricular pacemakers in heart failure patients. J Cardiovasc Electrophysiol. 2008; 19:693-701. | Article | PubMed

44. Doliwa Sobocinski P, Anggardh Rooth E, Frykman Kull V, von Arbin $\mathrm{M}$, Wallen $\mathrm{H}$ and Rosenqvist $\mathrm{M}$. Improved screening for silent atrial fibrillation after ischaemic stroke. Europace. 2012; 14:1112-6. | Article I PubMed

45. Rizos T, Wagner A, Jenetzky E, Ringleb PA, Becker R, Hacke W and Veltkamp R. Paroxysmal atrial fibrillation is more prevalent than persistent atrial fibrillation in acute stroke and transient ischemic attack patients. Cerebrovasc Dis. 2011; 32:276-82. | Article | PubMed

46. Pisters R, de Vos CB, Dennert R and Crijns HJ. Undetected paroxysmal atrial fibrillation in chronic heart failure patients: is it clinically relevant to catch the atrial phantom? Europace. 2009; 11:1257-9. | Article | PubMed

47. Rho RW and Page RL. Asymptomatic atrial fibrillation. Prog Cardiovasc Dis. 2005; 48:79-87. | Article | PubMed

48. Sudlow M, Rodgers H, Kenny RA and Thomson R. Population based study of use of anticoagulants among patients with atrial fibrillation in the community. BMJ. 1997; 314:1529-30. | Article | PubMed Abstract | PubMed Full Text

49. Collerton J, Davies K, Jagger C, Kingston A, Bond J, Eccles MP, Robinson LA, Martin-Ruiz C, von Zglinicki T, James OF and Kirkwood TB. Health and disease in $\mathbf{8 5}$ year olds: baseline findings from the Newcastle 85+ cohort study. BMJ. 2009; 339:b4904. | Article | PubMed Abstract | PubMed Full Text

50. Samol A, Masin M, Gellner R, Otte B, Pavenstadt HJ, Ringelstein EB, Reinecke $\mathrm{H}$, Waltenberger $\mathrm{J}$ and Kirchhof $\mathrm{P}$. Prevalence of unknown atrial fibrillation in patients with risk factors. Europace. 2013; 15:657-62. | Article | PubMed

\section{Citation:}

Clua-Espuny JL, Bosch-Princep R, Roso-Llorach A, López-Pablo C, Giménez-Garcia E, González-Rojas N, Lucas-Noll J, Panisello-Tafalla A, Lechuga-Duran I and Gallofré-Lopez M. Diagnosed, undiagnosed and overall atrial fibrillation research on population over 60 year-old. AFABE study. Cardio Vasc Syst. 2014; 2:2. http://dx.doi.org/10.7243/2052-4358-2-2 